\title{
PERANCANGAN SISTEM INFORMASI ADMINISTRASI PEMELIHARAAN PESAWAT TERBANG MILITER PADA SKADRON TEKNIK (SKATEK) 021
}

\author{
Indarwati, Dimpo Sinaga
}

\begin{abstract}
Advances in information technology, access to data or information available can take place quickly, efficiently and accurately. The rapid technological developments have enabled the air media widely for various purposes and created a new force known as air power.

According to the doctrine of air power, air control air capability, air attack, air support with various modifications according to the needs and needs of each country. Aircraft that require air power of various types, types and functions is the type of hunter / combat aircraft, reconnaissance, bombers, and transport aircraft.

What can be done to transport personnel and equipment such as weaponry in the soonest possible time. In the context of Scheduling, speed and accuracy. Measurement tool readiness unit operation unit.
\end{abstract}

\section{PENDAHULUAN}

Kemajuan teknologi informasi, pengaksesan terhadap data atau informasi yang tersedia dapat berlangsung dengan cepat, efisien dan akurat. Perkembangan teknologi yang sangat pesat telah memungkinkan pemanfaatan media udara secara luas untuk berbagai kepentingan dan memunculkan suatu kekuatan baru yang dikenal sebagai kekuatan udara.

Menurut doktrin air power, kemampuan kekuatan udara meliputi pengendalian udara (control of the air), penyerangan udara (air strike), dan dukungan udara (air support) dengan berbagai modifikasi sesuai kepentingan dan kebutuhan setiap negara. Pesawat-pesawat udara yang mengisi kekuatan udara terdiri dari berbagai macam, jenis dan fungsi diantaranya adalah jenis pesawat pemburu/fighter, pengintai, bombers, dan pesawat angkut.

Mobilitas dari konsentrasi kekuatan dan peralatan yang baik dapat di capai dengan adanya pesawat-pesawat angkut yang dapat melaksanakan pengangkutan personel maupun perlengkapan seperti persenjataan dalam waktu secepat mungkin. Dalam konteks pemeliharaan, kecepatan dan ketepatan pemeliharaan alat utama sistem persenjataan udara (alutsistaud) menjadi alat ukur kesiapan operasi suatu satuan.

Aspek pemeliharaan selain personel sebagai subyek dan objek, juga mencakup prosedurprosedur pemeliharaan tertulis dan tidak tertulis. Prosedur tertulis dicantumkan di dalam bentuk buku pemeliharaan (manual book), check list atau maintenance update yang diterbitkan oleh perusahaan pembuat peralatan sedangkan prosedur tidak tertulis, tindakan pemeliharaan yang dilakukan diluar buku petunjuk pemeliharaan yang dikeluarkan oleh yang berwenang. Pemeliharaan alutsistaud adalah suatu seni yang membutuhkan keahlian, kesabaran, pengalaman dan inovasi berkesinambungan dari waktu ke waktu.

Salah satu satuan pemeliharaan pesawat terbang Tentara Nasional Indonesia Angkatan Udara (TNI AU) yaitu di Skadron Teknik (Skatek) 021. Skatek 021 merupakan satuan pemeliharaan milik TNI AU yang terletak di Pangkalan Udara (Lanud) Halim Perdanakusuma Jakarta untuk tingkat sedang yang digunakan dalam melakukan pemeliharaan pesawat terbang jenis angkut, seperti B737-200/400, CN-235/295, C-130, dan F-28.

Berdasarkan latar belakang diatas, dengan adanya sistem informasi dalam administrasi pemeliharaan pesawat terbang diharapkan dapat memberikan kemudahan dalam pengarsipan pemeliharaan pesawat terbang dan dapat mengetahui data pesawat terbang yang telah dilakukan pemeliharaan yang terdapat di Skatek 021 .

\section{Metoda Penelitian}

a. Wawancara

Penulis melakukan wawancara terhadap pihak yang terdapat di Skatek 021 Lanud Halim Perdanakusuma. Penulis melakukan wawancara kepada yang berkaitan dengan 
apa yang ditulis.

b. Studi Pustaka

Penulis mencari informasi yang berhubungan dan terkait dengan yang ditulis agar mendukung teori yang dituliskan.

\section{Pembahasan Masalah}

Mengidentifikasi masalah merupakan tahapan awal untuk mengetahui masalah dari kelemahan di latar belakang yang dihadapi dalam perancangan informasi. Dalam melakukan administrasi pemeliharaan pesawat terbang di Skatek 021 masih dengan manual yaitu dengan pengarsipan file dalam bentuk kertas, jika suatu ketika data dibutuhkan segera, harus melihat dan mencari di arsip terlebih dahulu.

Dalam melakukan pemeliharaan pesawat yang akan dipelihara, ditulis di sebuah papan tulis yang disediakan, agar dapat memantau pesawat yang sedang dilakukan pemeliharaan. Jika pesawat sudah selesai pemeliharaan catatan yang ada dihapus untuk diganti yang baru.

Jadi, Bagaimana membuat sistem informasi administrasi pemeliharaan pesawat terbang militer pada Skadron Teknik (Skatek) 021?

\section{Landasan Teori}

Analisa dan Perancangan metodologi terstuktur

\section{Analisa Sistem}

Analisa sistem merupakan proses awal yang harus dilaksanakan untuk menentukan permasalahan yang sedang dihadapi. Tahap ini adalah sangat penting, karena proses analisis yang kurang akurat menyebabkan hasil dari pengembangan perangkat lunak akan tidak sesuai dengan yang diharapkan.

Analisa sistem adalah penguraian dari suatu sistem informasi yang utuh ke dalam bagianbagian komponennya dengan maksud untuk mengidentifikasikan dan mengevaluasi permasalahan, kesempatan, hambatan yang terjadi dan kebutuhan yang diharapkan sehingga dapat diusulkan perbaikannya.

Analisa sistem didefinisikan sebagai memahami dan menspesifikasikan dengan detail apa yang harus dilakukan oleh sistem. Sementara sistem desain diartikan sebagai menjelaskan dengan bagaimana bagian-bagian dari sistem informasi diimplementasikan.

\section{Perancangan Sistem}

Perancangan adalah proses penerapan berbagai teknik dan prinsip yang bertujuan untuk mendefinisikan sebuah peralatan, satu proses atau sistem secara detail yang membolehkan dilakukan realisasi fisik. Analisa dan Desain (ANSI) didefinisikan proses organisasional kompleks dimana sistem berbasis komputer dapat diimplementasikan.

\section{Metodologi Terstuktur}

Metodologi adalah prosedur dalam pemecahan masalah dari sistem yang ada untuk membangun sebuah sistem yang baru. Terdapat banyak metodologi yang dapat digunakan dalam desian dan pengembangan informasi seperti: System Development Life Cycle (SDLC), Rapid Application Development (RAD), Object Otiented Analysis and Desaign, Prototyping, etc (Dennis, Wixom Teargarden, 2012).

Teknik dasar metode terstuktur sebagai berikut:

1) Dekomposisi fungsional dengan pendekatan Top down

2) Metodologi ini membutuhkan keterlibatan pengguna dalam sistem dari awal sampai akhir

3) Dua konsen utama dalam pengembangan sebuah sistem informasi adalah proses dan data yang dimodelkan. Proses dimodelkan dengan menggunakan Data Flow Diagram (DFD) dan data store (media penyimpanan data) dan proses alirannya dari sumber data ke tujuan. Model data didefinisikan dengan menggunakan Entity Relationship Diagram (ERD).

4) Independensi antara modeling data dan proses berlanjut sampai pada tahap desain.

Kelebihan dan kekurangan metode terstuktur

1) Kelebihan

- Metodologi terstuktur merupakan pendekatan visual, ini membuat metode ini mudah di mengerti oleh pengguna atau programmer

- Pengunaan analisis grafis dan tool seperti DAD menjadikan metodologi terstuktur terlihat bagus

- Metode diketahui secara umum

- Metode ini layak digunakan karena sudah lama diterapkan

- Memungkinkan validasi antara berbagai kebutuhan 
- Simpel dan mudah dimengerti

\section{2) Kekurangan}

- Berorientasi pada proses, sehingga mengabaikan kebutuhan non fungsional

- Sedikit sekali manajemen langsung terkait

- Prinsip dasar merupakan pengembangan non-interative (waterfall)

- Interaksi antara analisis atau pengguna tidak komprehensif, karena sistem telah didefinisikan dari awal, sehingga tidak adaptive terhadap perubahan

- Selain dengan menggunakan desain logic dan DAD, tidak cukup tool yang digunakan untuk mengkomunikasikan dengan pengguna.

- Sulit untuk memutuskan ketika ingin menghentikan dekomposisi dan mulai membuat baru

- Tidak selalu memenuhi pengguna dan tidak dapat memenuhi kebutuhan terkait bahasa pemograman berorientasi objek, karena metode ini di desain untuk metode terstuktur.

\section{System Development Life Cycle (SDLC)}

Pengembangan sistem berarti menyusun suatu sistem yang baru untuk menggantikan sistem yang lama secara keseluruhan atau memperbaiki sistem sistem yang telah ada (Jogiyanto, 1999). Siklus Hidup Pengembangan Sistem merupakan penerapan pendekatan sistem untuk mengembangkan dan menggunakan sistem berbasis komputer.

Menurut Pressman membagi tahapan SDLC dalam 4 tahap yaitu : analysis, design, code, dan test. Model SDLC memiliki beberapa kelemahan, yaitu:

Terjadinya pembagian proyek menjadi tahaptahap yang tidak fleksibel, karena komitmen harus dilakukan pada tahap awal proses,

a. Dapat mengakibatkan sulitnya merespons perubahan kebutuhan pengguna.

b. Model SDLC harus digunakan hanya ketika persyaratan dipahami dengan baik.

Tahap-tahap SDLC dalam pembangunan sistem informasi :
a. Perencanaan
Tahap ini yaitu membuat perencanaan

dengan mengumpulkan bahan serta studi kelayakan sesuai dengan kebutuhan sistem.

b. Analisa

Tahap ini digunakan untuk menganalisa seluruh kebutuhan sistem untuk usulan sistem informasi. Dengan menetapkan kemampuan yang diperlukan untuk kebutuhan pengguna akhir, yang berguna untuk menyelesaikan tahap perancangan sistem.

c. Desain

Rancangan ini terdiri dari rancangan logika dan fisik yang dapat menghasilkan spesifik sistem yang dikembangkan pada tahap analisa sistem.

d. Implementasi

Tahap ini melakukan pengecekan sebelum sistem benar-benar dapat diterapkan dengan melalui testing atau uji kehandalan dari sistem.

e. Pemeliharaan system.

Adapun beberapa tahap yang dilakukan :

1) Memperbaiki desain yang error pada program sistem informasi

2) Memodifikasi sistem untuk beradaptasi dengan perubahan lingkungan

3) Menjaga sistem dari masalah yang akan mendatang.

\section{ANALISA SISTEM \\ Proses Prosedur Administrasi Pemeliharaan Pesawat}

Proses administrasi pemeliharaan pesawat yaitu Skadron Udara (Skadron) membuat nota dinas kepada Kadislog (Kepala Dinas Logistik) untuk permohonan pemeliharaan, setelah itu Kadislog mengirimkan Perintah Kerja Utama (PKU) untuk Skatek 021, agar melakukan pemeliharaan sesuai prosedur. Setelah itu Skadron mengirimkan pesawat yang akan dilakukan pemeliharaan ke Skatek 021 dengan melakukan serah terima pesawat terbang dari Skadron.

Data pesawat terbang disimpan dalam bentuk hardcopy atau pengarsipan serta data pesawat terbang yang akan dilakukan pemeliharaan juga ditulis di papan yang ada, untuk mengingatkan pesawat yang sedang dilakukan pemeliharaan atau jadwal pemeliharaan yang akan datang. Pemeliharaan dilakukan lebih dari 1 (satu) kali sesuai jenis inspeksinya dan dilakukan secara bertahap sesuai perencanaan pemeliharaan. Hal seperti ini membutuhkan tempat penyimpanan yang cukup besar dan pencariannya pun harus dilakukan satu persatu dan menjadikan 
kurang effektif dan efisien waktu, jika membutuhkan informasi tentang data pemeliharaan pesawat.

\section{Analisa Proses}

\section{a. Proses Bisnis}

Skatek 021 selaku satuan pelaksana dibawah jajaran Lanud Halim Perdanakusuma memiliki tugas pemeliharaan menyelenggarakan pembinaan pemeliharaan Alat Utama Sistem Senjata (Pesawat Terbang) beserta komponennya, khususnya perawatan tingkat sedang pesawat CN235-1 00/200M, CN295M, F-28Mk 1000/3000/4000, B373 200/400 dan C1 30H/HS/L- 100-30, yang diselenggarakan secara sistematis, terencana, terpadu dan berkesinambungan mencakup pemeliharaan terjadwal serta tidak terjadwal, sehingga kesiapan pesawat dapat terdukung secara optimal sesuai dengan yang direncanakan.

Prosedur kerja yang ada pada sistem yang berjalan pada Skatek 021 adalah sebagai berikut:

1. Skatek 021 menerima Perintah Kerja Utama (PKU) dari Kadislog

2. Skatek 021 melakukan serah terima pesawat dari skadron, serta membuat perencanaan pemeliharaan pesawat.

3. Personel TNI AU melakukan pemeliharaan di Skatek 021 dan membuat hasil pemeliharaan dan diserahkan kepada bagian Tata Usaha Teknik (TUT)

4. TUT membuat Surat Keterangan Lulus Pesawat Terbang beserta berkas yang lainnya untuk di serahkan kepada skadron dan Kadislog.

\section{b. Flowmap}

Penggambaran secara grafik dari langkahlangkah dan secara grafik dari langkahlangkah dan urut-urutan dari suatu program.

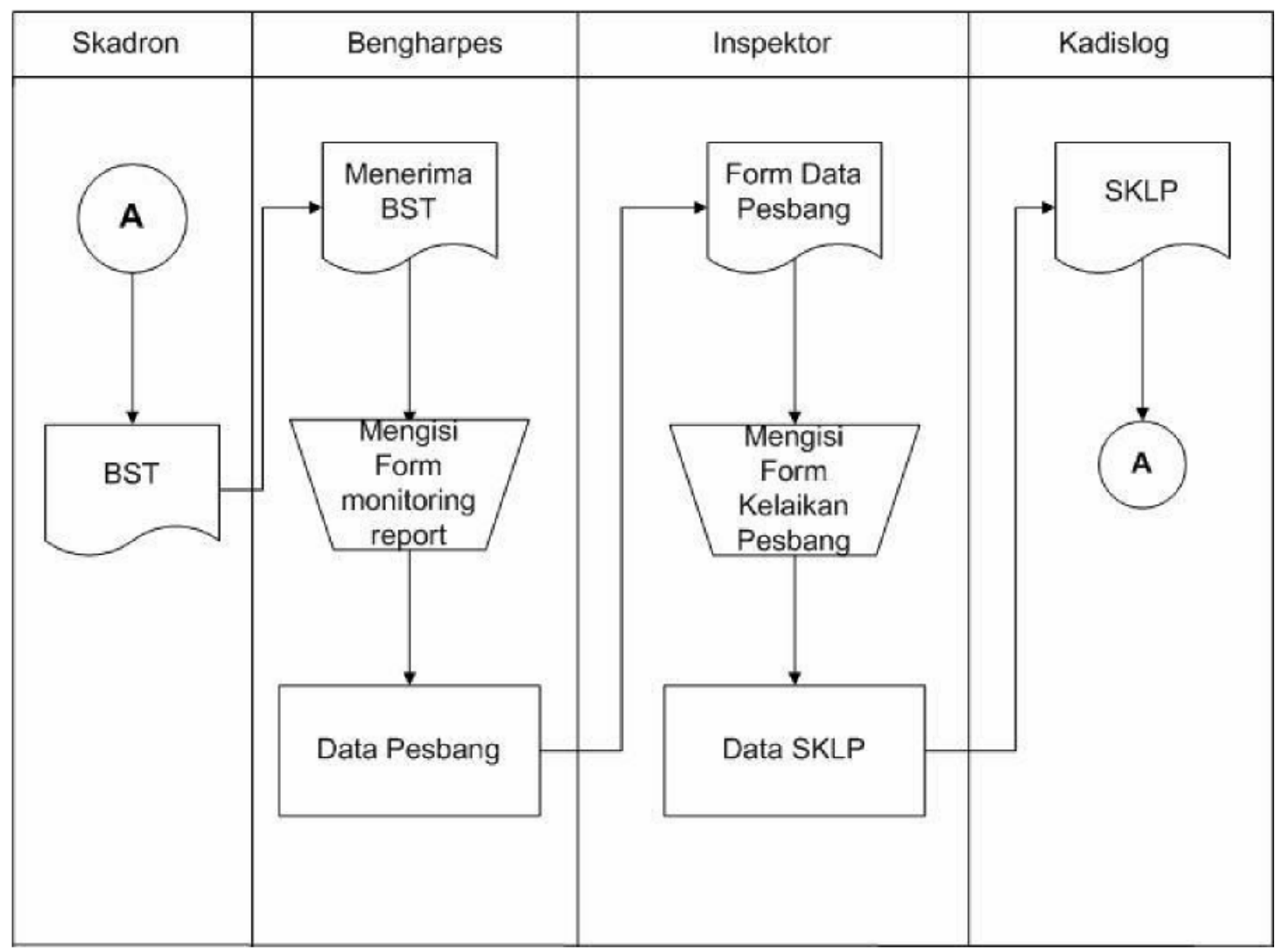

Gambar 3.2 Flowmap sistem yang berjalan 
c. DAD Sistem Berjalan

1) Diagram Konteks Sistem Berjalan

Diagram konteks merupakan pola penggambaran yang berfungsi untuk memperlihatkan interaksi sistem informasi dengan lingkungan dimana sistem tersebut ditempatkan. Sistem dimaksud adalah untuk menggambarkan sistem berjalan. Mengidentifikasikan awal dan akhir yang masuk dan keluaran sistem.

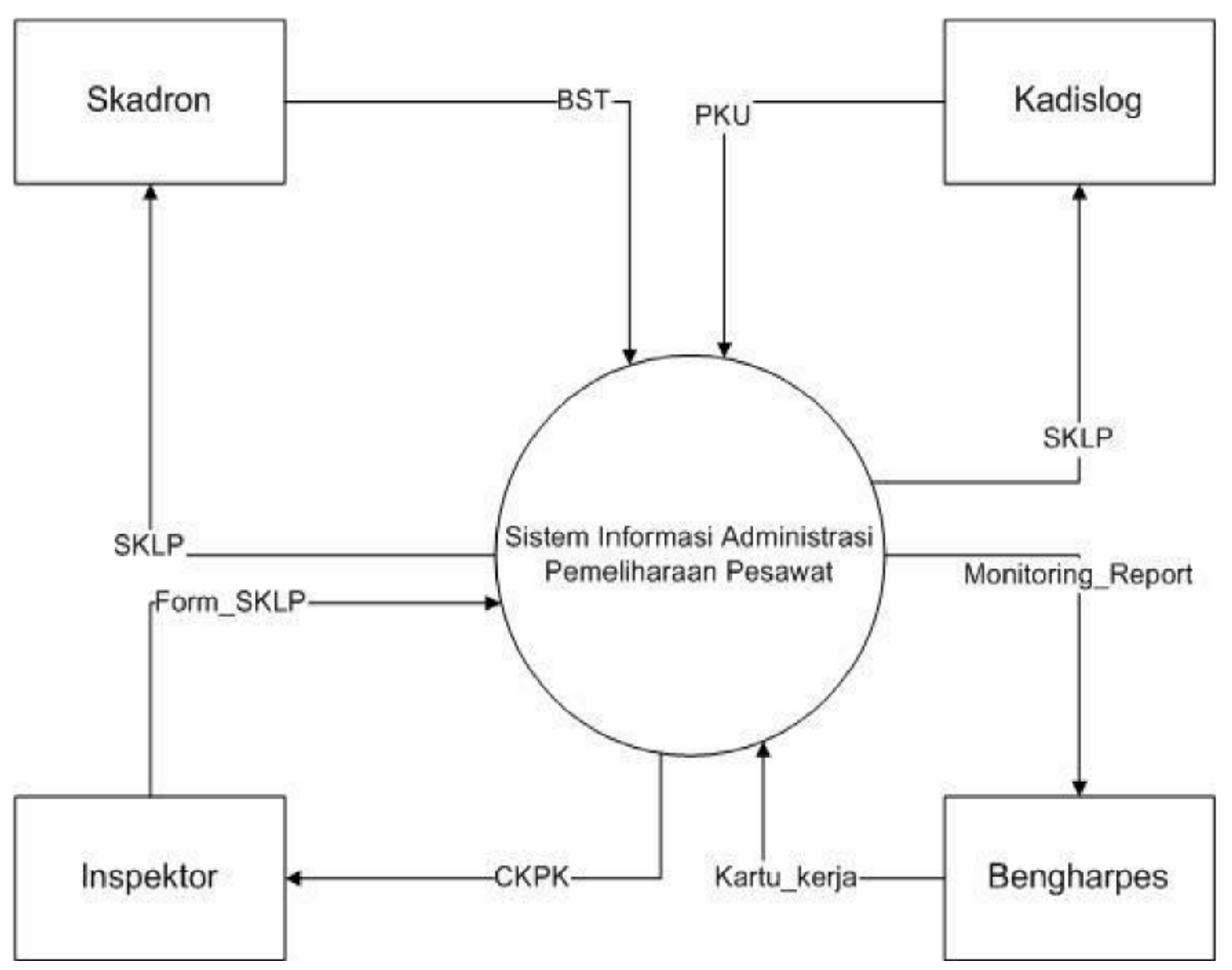

Gambar 3.3 Diagram Konteks sistem yang berjalan

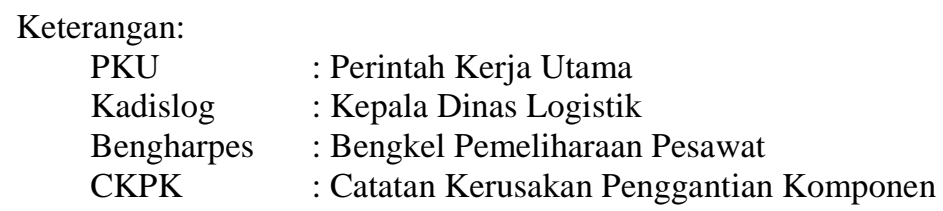

2) Diagram Nol Sistem Berjalan

Diagram nol adalah diagram yang menggambarkan proses dari Diagram Alur Data (DAD). Diagram nol memberikan pandangan secara menyeluruh mengenai sistem yang ditangani, menunjukan tentang fungsifungsi utama atau proses yang ada, aliran data, dan external entity. 


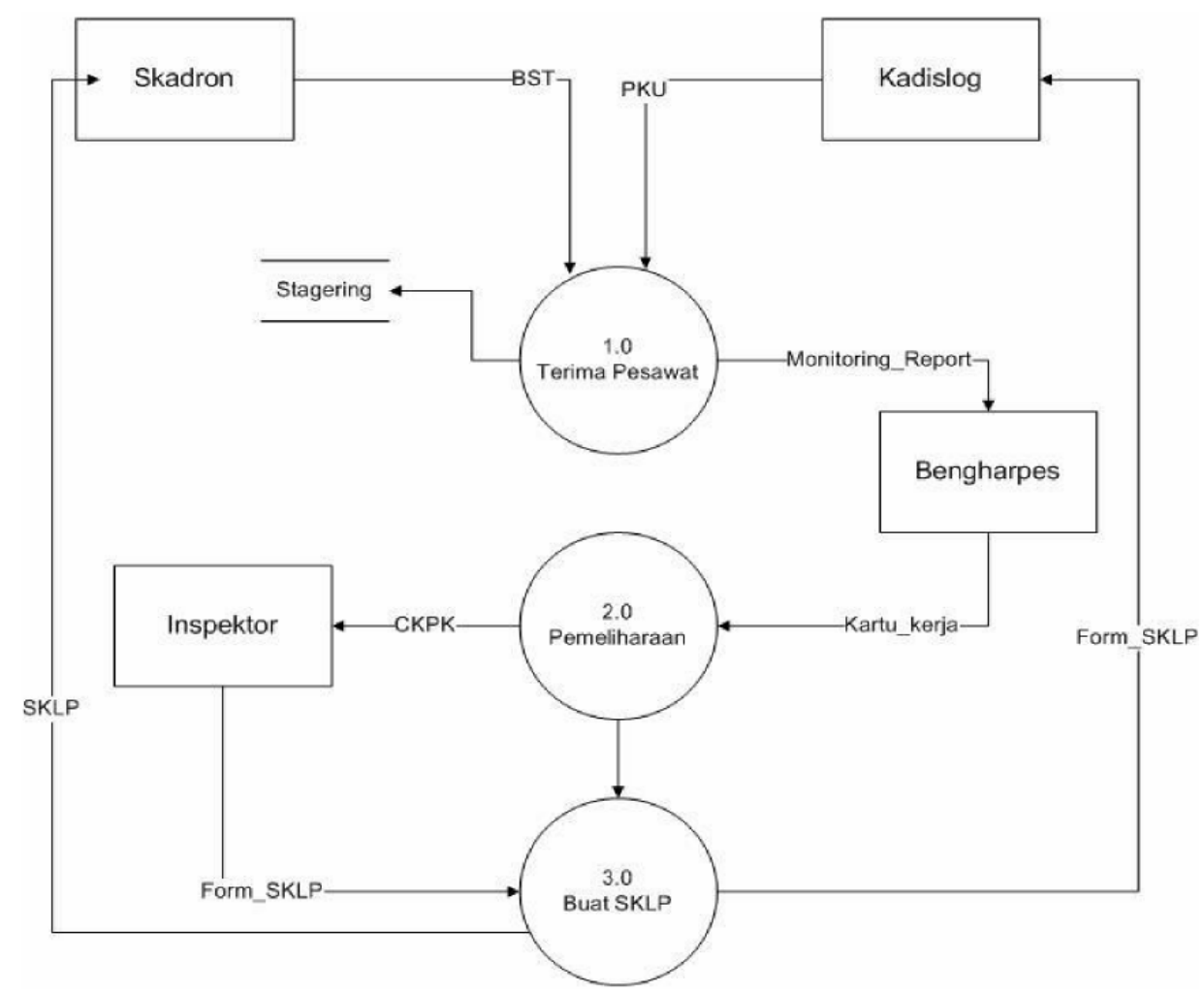

Gambar 3.4 Diagram Nol sistem berjalan

d. Uraian dari Spesifikasi Proses

$\begin{array}{ll}\text { 1. Nomor } & : 1.0 \\ \text { Nama } & : \text { Terima Pesawat } \\ \text { Masukan } & \text { Bukti Serah Terima (BST), } \\ & \text { PKU } \\ \text { Keluaran } & \text { Monitoring Report } \\ \text { Uraian } & \text { Informasi tentang Data pesa- } \\ & \text { wat terbang oleh skadron } \\ & \text { dan surat perintah tugas dari } \\ & \text { Kadislog. Terdiri pekerjaan, } \\ \text { pelaksana, tangal (mulai, } & \text { selesai), nodin, no pku, dan } \\ & \text { keterangan. }\end{array}$

2. Nomor : 2.0

Nama : Pemeliharaan

Masukan : Kartu Kerja

Keluaran : CKPK

Uraian : Informasi pesawat terbang yang dilakukann pemeliharaan, Catatan kerusakan \& penggantian komponen. Terdiri dari Type sista, no reg, Satgun, gangguan, tindakan, mekanik, inspektor
3. Nomor : 3.0

Nama : Buat SKLP

Masukan : Form_SKLP

Keluaran : SKLP

Uraian : SKLP Merupakan Surat Keterangan Lulus Pesawat Terbang yang digunakan untuk bukti bahwa pesawat tersebut layak terbang. Terdiri dari : Pesawat, No seri, No reg, Kesatuan, Keterangan, Tanggal, Dilaksanakan oleh, Diluluskan Oleh

\section{Analisa Keluaran}

Nama Keluaran : Surat Keterangan Lulus Pesawat Terbang

Fungsi : Sebagai surat atau keterangan lulus pesawat terbang setelah dilakukan pemeliharaan di Skatek 021

Media : Kertas

Distribusi : Skadron, Inspektor, TUT

Rangkap : Tiga

Frekuensi : Setiap setelah pemeliharaan selesai dilakukan dan di- 
nyatakan bahwa pesawat tersebut layak terban

Volume : Setiap setelah melakukan pemeliharaan pesawat terbang

Format

: Lampiran A-1

Hasil Analisa : Dalam hal pembuatan menggunakan Ms Word sehingga kurang effektif dalam pekerjaan dan penyimpanan dalam bentuk kertas, tidak terkomputerisasi.

\section{Analisa masukan}

a. Nama Masukan : Bukti Serah Terima Pesbang

Sumber : Skadron

Fungsi : Sebagai dasar dan bukti penerimaan dari pihak Skadron kepada pihak Skatek 021

Media : Kertas

Rangkap : Satu

Frekuensi : Setiap akan mulai melakukan tahap awal pemeliharaan

Volume : Setiap akan terjadi pemeliharaan

Keterangan : -

Hasil Analisa : Bukti serah terima sebagai data masukan pesawat terbang di simpan sebagai arsip dan dicatat dalam buku riwayat pesawat sesuai data komponennya dalam bu$\mathrm{ku}$ riwayat, jadi belum terkomputerisasi.

b. Nama Masukan : PKU

Sumber : Kadislog

Fungsi : Perintah dan dasar untuk me-lakukan pemeliharaan
Media : Kertas

Rangkap : Satu

Frekuensi : Setiap akan mulai melakukan tahap awal pemeliharaan

Volume $\quad$ : Setiap akan terjadi pemeliharaan

Hasil Analisa : Setiap menerima Pku dicatat dan disimpan dalam file takah sesuai dengan nama dan jenis file takahnya.

\section{Analisa Data}

Nama Data Store : Stagering

Deskripsi

: Kumpulan data yang berisi tentang data pesawat yang dilakukan pemeliharaan

Media $\quad$ : Papan Tulis Kaitan dengan data masukan : Dibuat berdasarkan data pesawat terbang yang diterima Kaitan dengan data keluaran : Digunakan untuk monitoring pesawat dari mulai dan selesai pemeliharaan

Deskripsi data : No reg pesawat, jenis pes, no seri, tanggal perencanaan, tanggal pelaksanaan, keterangan.

\section{Spesifikasi Basis Data}

$\begin{array}{ll}\text { 1) Nama File } & \text { : Skadron } \\ \text { Media } & \text { : File } \\ \text { Isi } & \text { : Data User } \\ & \text { ra) } \\ \text { Organisasi } & :- \\ \text { Primary Key } & : \text { nama_skd } \\ \text { Panjang record } & : 40 \\ \text { Jumlah Field } & : 2 \\ \text { Stuktur } & :\end{array}$

Tabel 4.7 Tabel Skadron

\begin{tabular}{|c|l|l|l|l|l|}
\hline No & \multicolumn{1}{|c|}{ Nama Field } & \multicolumn{1}{|c|}{ Jenis } & \multicolumn{1}{|c|}{ Lebar } & Desimal & Keterangan \\
\hline 1 & Nama_skd & Text & 15 & & Primay Key \\
\hline 2 & Alamat & Text & 25 & & \\
\hline
\end{tabular}

2) Nama File : PKU

Media : File

Isi : Data PKU

Organisasi :

Primary Key : no_pku

Panjang record : $: 50$

Jumlah Field : : 3

Stuktur 
Tabel 4.8 Tabel pku

\begin{tabular}{|l|l|l|l|l|l|}
\hline No & Nama Field & Jenis & Lebar & Desimal & Keterangan \\
\hline 1 & No_pku & Text & 15 & & Primay Key \\
\hline 2 & Tanggal & Date & 10 & & \\
\hline 3 & Keterangan & Text & 25 & & \\
\hline
\end{tabular}

3) Nama File : pesawat

Media : File

Isi : Data pesawat

Organisasi :

Primary Key : no_reg

Panjang record : $: 27$

Jumlah Field : : 3

Stuktur

Tabel 4.9 Tabel pesawat

\begin{tabular}{|l|l|l|l|l|l|}
\hline No & Nama Field & Jenis & Lebar & Desimal & Keterangan \\
\hline 1 & No_reg & Text & 10 & & Primay Key \\
\hline 2 & Jenis_pes & Text & 10 & & \\
\hline 3 & No_seri & Text & 10 & & \\
\hline
\end{tabular}

4) Nama File : BST

Media : File

Isi : Data Pesawat yang diterima

Organisasi :

Primary Key : No_terima

Panjang record : 162

Jumlah Field $\quad: 13$

Stuktur

Tabel 4.10 Tabel BST

\begin{tabular}{|l|l|l|l|l|l|}
\hline No & Nama Field & Jenis & Lebar & Desimal & Keterangan \\
\hline 1 & No_Terima & AutoNumber & 5 & & Primary Key \\
\hline 2 & No_reg & Text & 10 & & Foreign Key \\
\hline 3 & Jenis_pes & Text & 10 & & \\
\hline 4 & No_seri & Text & 10 & & \\
\hline 5 & Usia_pes & Number & 12 & & \\
\hline 6 & Usia_landing & number & 12 & & \\
\hline 7 & Diserahkan_oleh & Text & 20 & & \\
\hline 8 & Usia_motor1 & Number & 12 & & \\
\hline 9 & Usia_motor2 & number & 12 & & \\
\hline 10 & Usia_motor3 & Number & 12 & & \\
\hline 11 & Usia_motor4 & Number & 12 & & \\
\hline 12 & Tanggal & Date & 10 & & \\
\hline 13 & Alas an & Text & 25 & & \\
\hline
\end{tabular}

5) Nama File : Pemeliharaan

Media $\quad$ : File

Isi : Data Pemeliharaan Pesawat 
Organisasi

Primary Key : no_har

Panjang record : 120

Jumlah Field $\quad: 8$

Stuktur

Tabel 4.11 Tabel Pemeliharaan

\begin{tabular}{|l|l|l|l|l|l|}
\hline No & Nama Field & Jenis & Lebar & Desimal & Keterangan \\
\hline 1 & No_har & AutoNumber & 5 & & Primary Key \\
\hline 2 & No_pku & Text & 15 & & Foreign Key \\
\hline 3 & No_reg & Text & 10 & & Foreign Key \\
\hline 4 & Jenis_pes & Text & 10 & & \\
\hline 5 & No_seri & Text & 10 & & \\
\hline 6 & mulai & Date & 10 & & \\
\hline 7 & selesai & Date & 10 & & \\
\hline 8 & Gangguan & Text & 25 & & \\
\hline 9 & Tindakan & Text & 25 & & \\
\hline
\end{tabular}

6) Nama File : SKLP

Media : File

Isi : Data kelulusan pesawat terbang

Organisasi :

Primary Key : :

Panjang record $: 125$

Jumlah Field $: 8$

Stuktur

Tabel 4.12 Tabel SKLP

\begin{tabular}{|l|l|l|l|l|l|}
\hline No & Nama Field & Jenis & Lebar & Desimal & Keterangan \\
\hline 1 & id & Autonumber & 5 & & Primary Key \\
\hline 2 & No_reg & Text & 10 & & Foreign Key \\
\hline 3 & Jenis_pes & Text & 10 & & \\
\hline 4 & No_seri & Text & 10 & & \\
\hline 5 & Kesatuan & Text & 15 & & \\
\hline 6 & Tanggal & Date & 10 & & \\
\hline 7 & Keterangan & Text & 25 & & \\
\hline 8 & Dock & Text & 20 & & \\
\hline 9 & Inspektor & Text & 20 & & \\
\hline
\end{tabular}




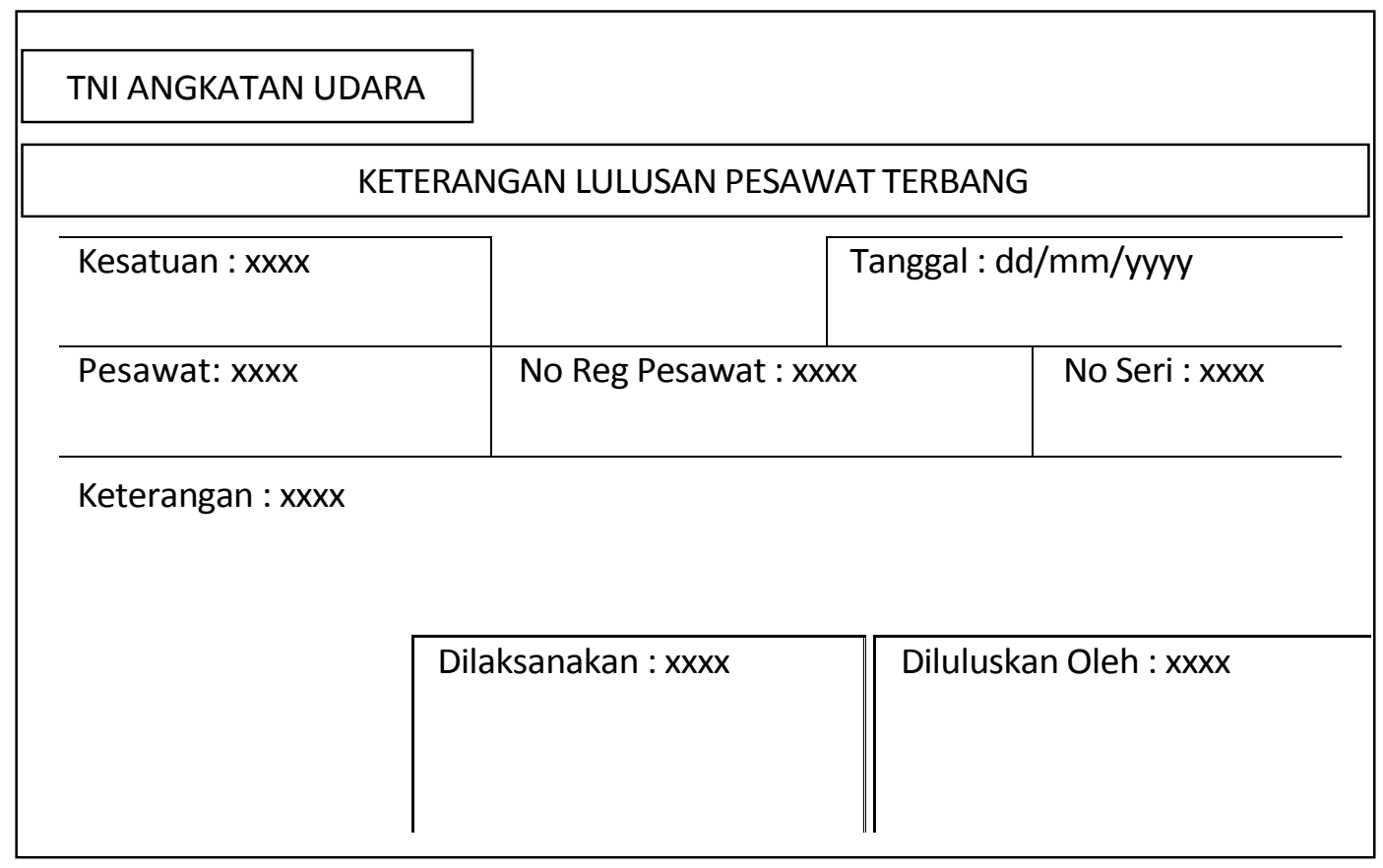

Gambar 4.13 Rancangan Bentuk Keluaran SKLP

\section{Rancangan kode}

1. Nama : id

Keterangan : Terdiri dari digit yang menunjukan urutan input

2. Nama : No_har

Keterangan : Terdiri dari digit yang menunjukan urutan masukan

\section{Rancangan Antar Muka}

a. Rancangan Keluaran

1) Rancangan Keluaran Surat Keterangan Lulus Pesawat Terbang

Nama Keluaran : Surat Keterangan Lulus Pesawat Terbang Fungsi : Sebagai urat atau keterangan lulus pesawat terbang setelah dilakukan pemeliharaan di Skatek 021

Media : Kertas, File

$\begin{array}{ll}\text { Distribusi } & \text { : Inspektor, Skadron, } \\ & \text { TUT } \\ \text { Rangkap } & : \text { Tiga } \\ \text { Frekuensi } & : \text { Setiap setelah peme- } \\ & \text { liharaan selesai di- } \\ & \text { lakukan dan dinyata- } \\ & \text { kan bahwa pesawat } \\ & \text { tersebut layak di- } \\ & \text { terbangkan kembali } \\ \text { Volume } & : \text { Setiap setelah me- } \\ & \text { lakukan pemeliharaan } \\ & \text { pesawat terbang } \\ \text { Format } & : \text { Dalam SKLP berja- } \\ \text { Keterangan } & : \text { Dalam } \\ & \text { lan terdapat list yang } \\ & \text { harus di ceklist tetap } \\ & \text { SKLP cukup kolom } \\ & \text { keterangan yang nanti } \\ & \text { berisi tentang apa } \\ & \text { yang dipelihara. }\end{array}$


2) Rancangan Keluaran Laporan Pemeliharaan

\begin{tabular}{|c|c|c|c|c|c|c|c|}
\hline \multicolumn{8}{|c|}{$\begin{array}{l}\text { SKADRON TEKNIK } 021 \text { LANUD HALIM PERDANAKUSUMA } \\
\text { LAPORAN DATA PEMELIHARAAN PESAWAT TERBANG } \\
\text { DD/M M/YYYY }\end{array}$} \\
\hline No Pemeliharaan & No PKU & No Reg & Jenis Pesawat & Mulai & Selesai & Gangguan & Tindakan \\
\hline 9999 & $x x x x$ & $x x x x$ & $x x x x$ & $\mathrm{Dd} / \mathrm{mm} / \mathrm{yy}$ & $\mathrm{Dd} / \mathrm{mm} / \mathrm{yy}$ & $x x x x$ & $x x x x$ \\
\hline 9999 & $x x x x$ & $x x x x$ & $x x x x$ & yy & yy & $x x x x$ & $x x x x$ \\
\hline 9999 & $x x x x$ & $x x x x$ & $x x x x$ & yy & yy & $x x x x$ & $x x x x$ \\
\hline 9999 & $x x x x$ & $x x x x$ & $x x x x$ & yy & yy & $x x x x$ & $x x x x$ \\
\hline 9999 & $x x x x$ & $x x x x$ & $x x x x$ & yy & yy & $x x x x$ & $x x x x$ \\
\hline
\end{tabular}

Gambar 4.14 Rancangan Bentuk Keluaran Lap Pemeliharaan

Nama Keluaran : Laporan Pemelihara-

an

Fungsi : Sebagai informasi untuk kepala bengkel dan sebagai data untuk mengetahui pemeliharaan dan data pesawat yang telah dilakukan pemeliharaan

Media : File, Kertas

Distribusi : Kabengharpes

Rangkap : Satu

Frekuensi : Setiap membutuhkan informasi pemeliharaan yang telah dilakukan

Volume : Setiap setelah melakukan pemeliharaan pesawat terbang

Format :

Keterangan :-

b. Rancangan Masukan

1) Nama Masukan : Bukti Serah Terima Pesbang

Sumber : User (Skadron Udara $2,17,31)$

Fungsi : Sebagai dasar dan bukti penerimaan dari pihak Skadron kepada pihak Skatek 021

Media : Kertas

Rangkap : : Satu

Frekuensi : Setiap akan mulai melakukan tahap awal pemeliharaan

Volume : Setiap akan terjadi pemeliharaan

Keterangan : Bukti serah terima dibuat oleh skadron udara untuk bukti penyerahan pesawat yang akan dilakukan oleh Skatek 021

2) Nama Masukan : PKU

Sumber : Kadislog

Fungsi : Perintah dan dasar dilakukan pemeliharaan

Media : Kertas

Rangkap : : Satu

Frekuensi : Setiap akan mulai melakukan tahap awal pemeliharaan

Volume : Setiap akan terjadi pemeliharaan 


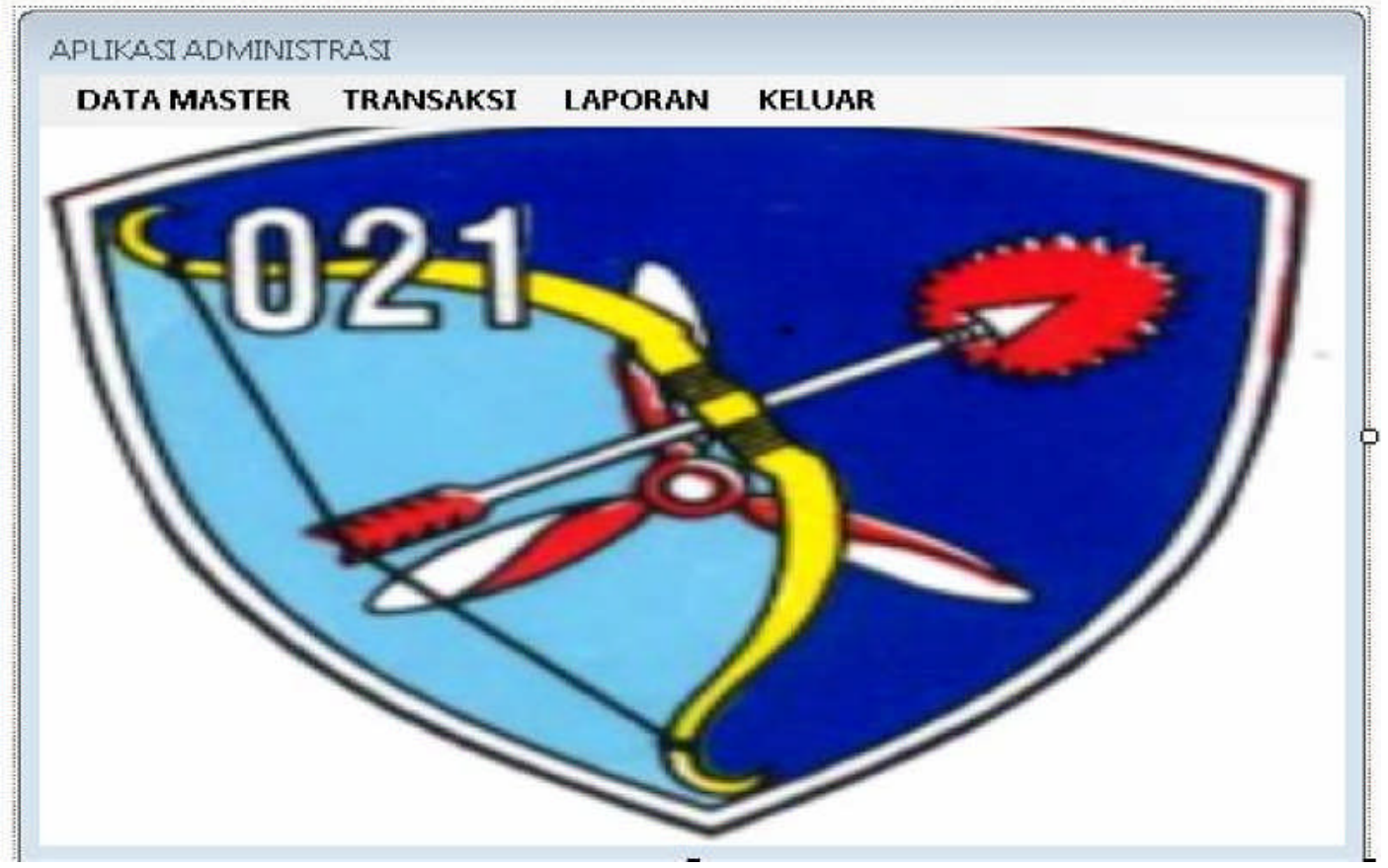

Stuktur tampilan menu utama

Pada stuktur tampilan form data pku berisikan mengenai data pku yang dikirimkan oleh kadislog sebagai dasar perintah kepada Skatek 021 untuk melakukan pemeliharaan.

\section{c) Stuktur tampilan Data Pku}

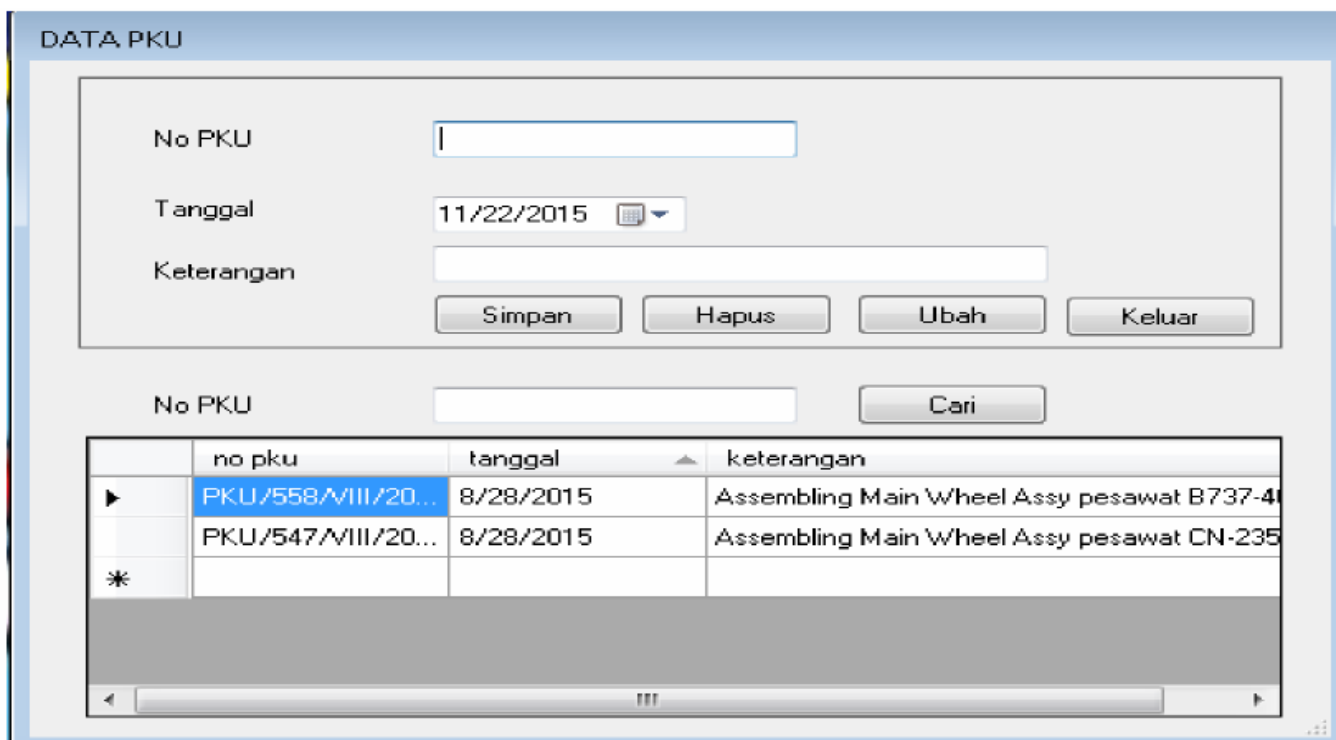

Stuktur tampilan Data Pku 
d) Stuktur tampilan Data Pesawat

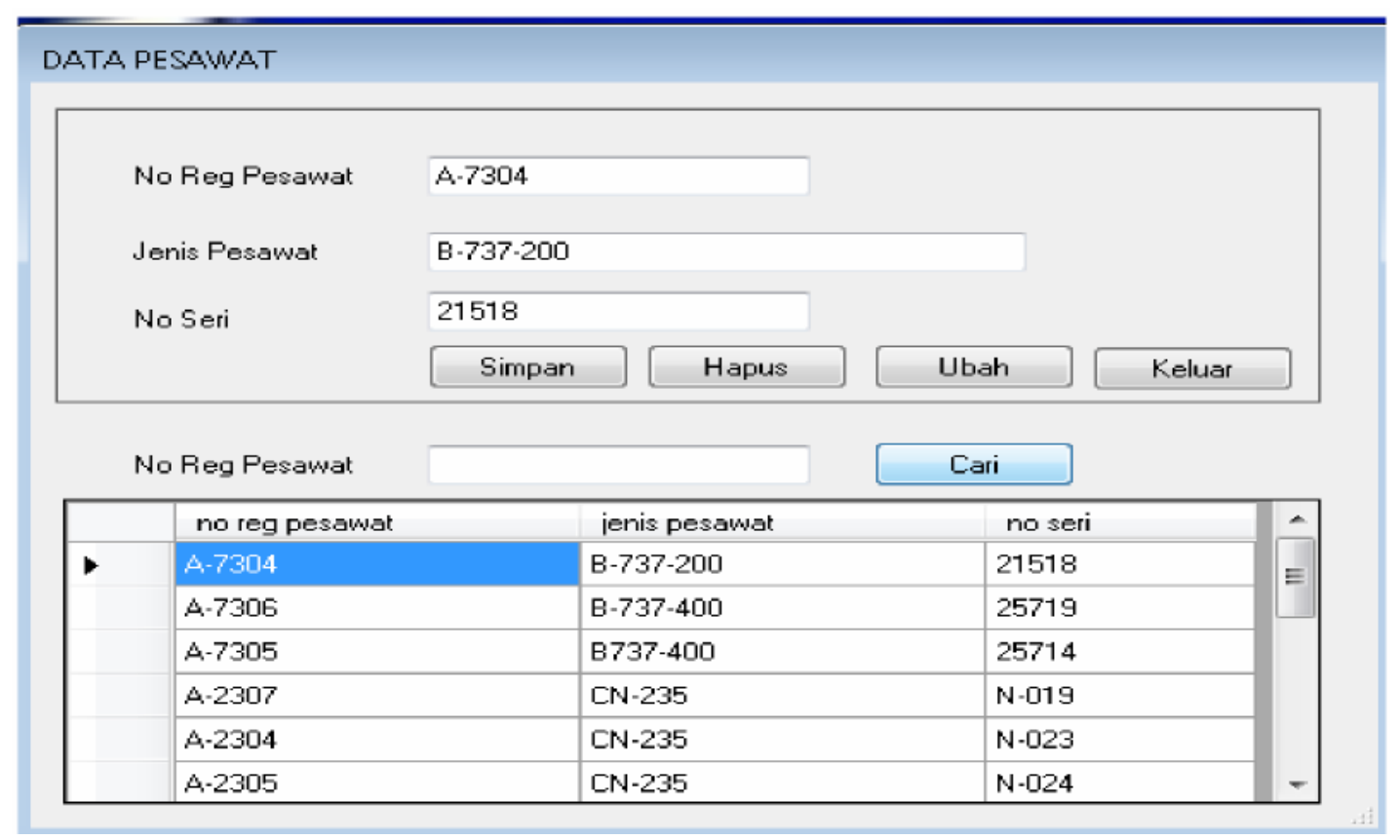

Stuktur tampilan Data Pesawat

e) Stuktur tampilan Data Penerimaan

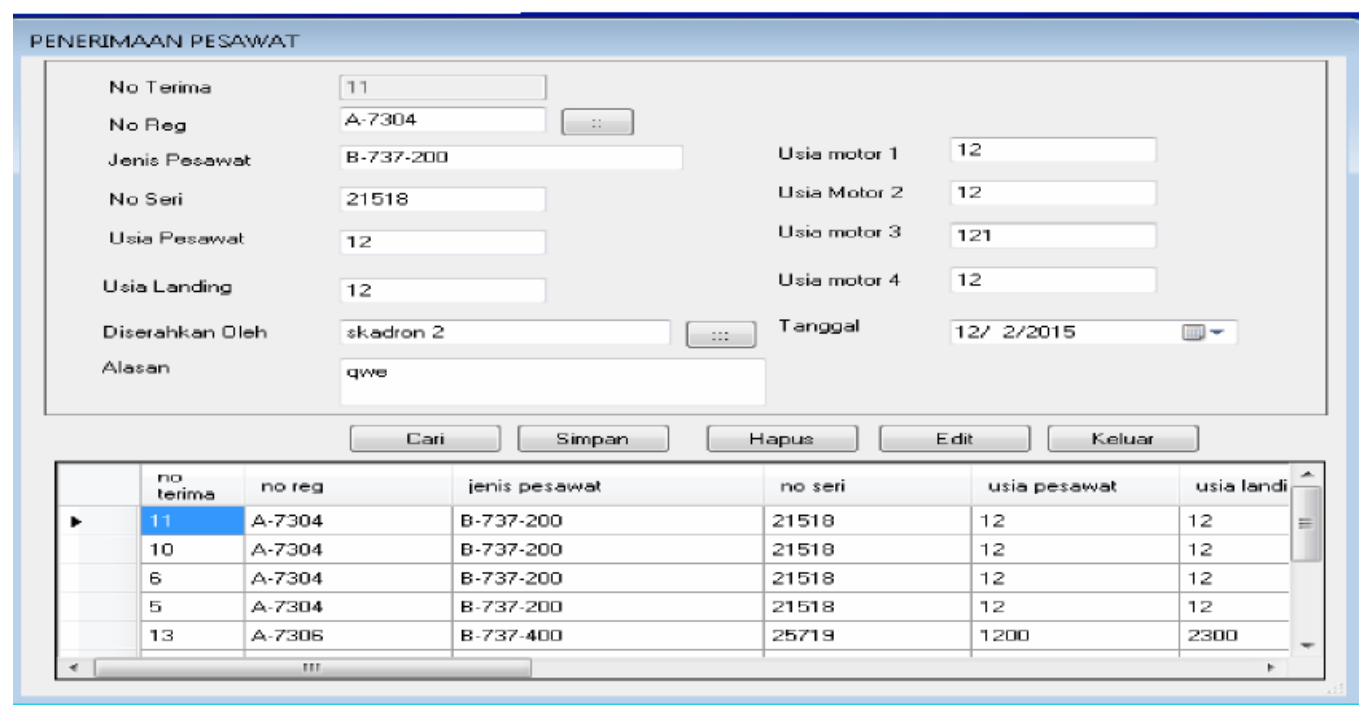

Stuktur tampilan Data Penerimaan 


\section{f) Stuktur tampilan Data Pemeliharaan}

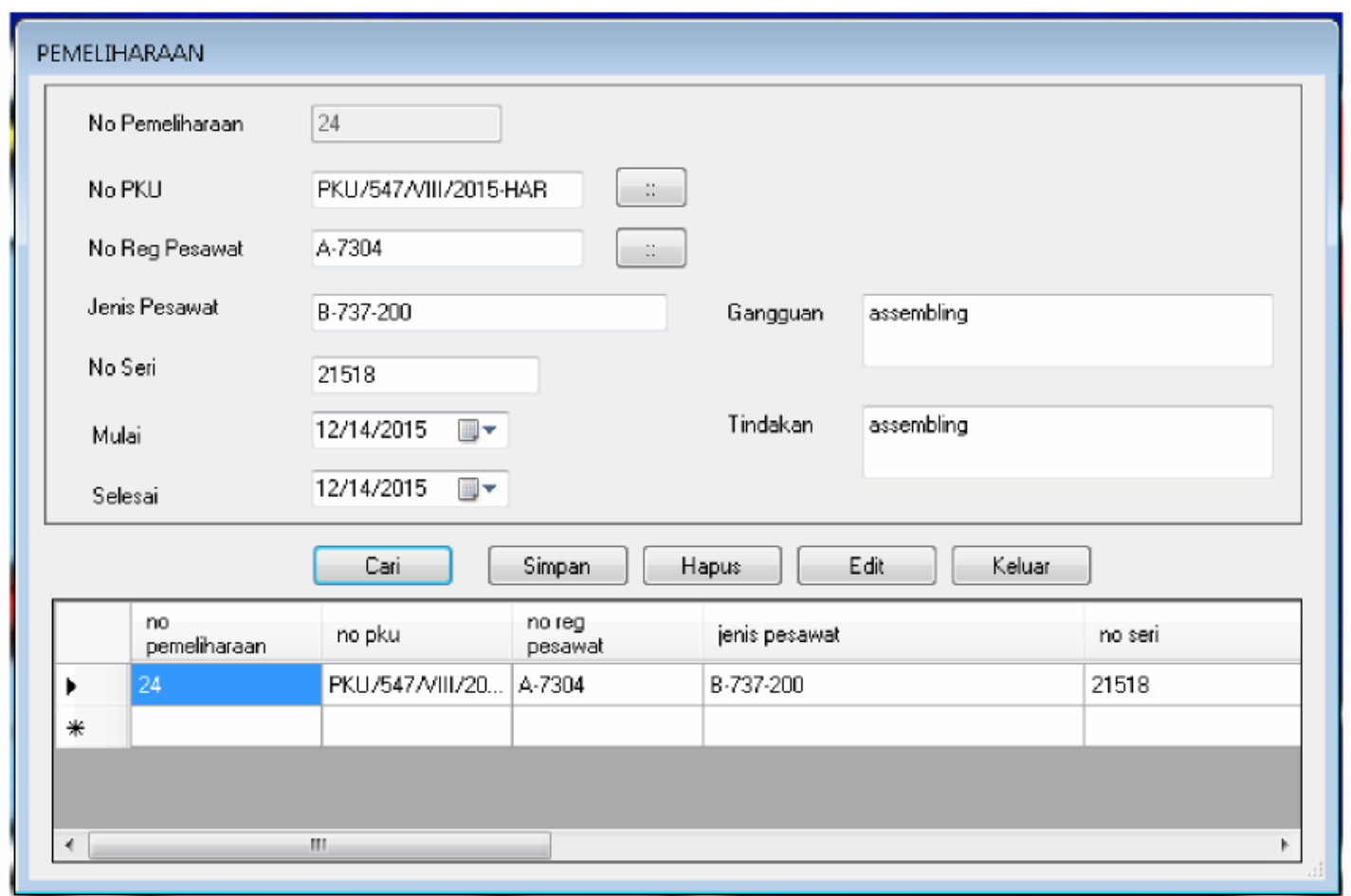

Stuktur tampilan Data Pemeliharaan

\section{g) Stuktur tampilan Lulus Kelaikan}

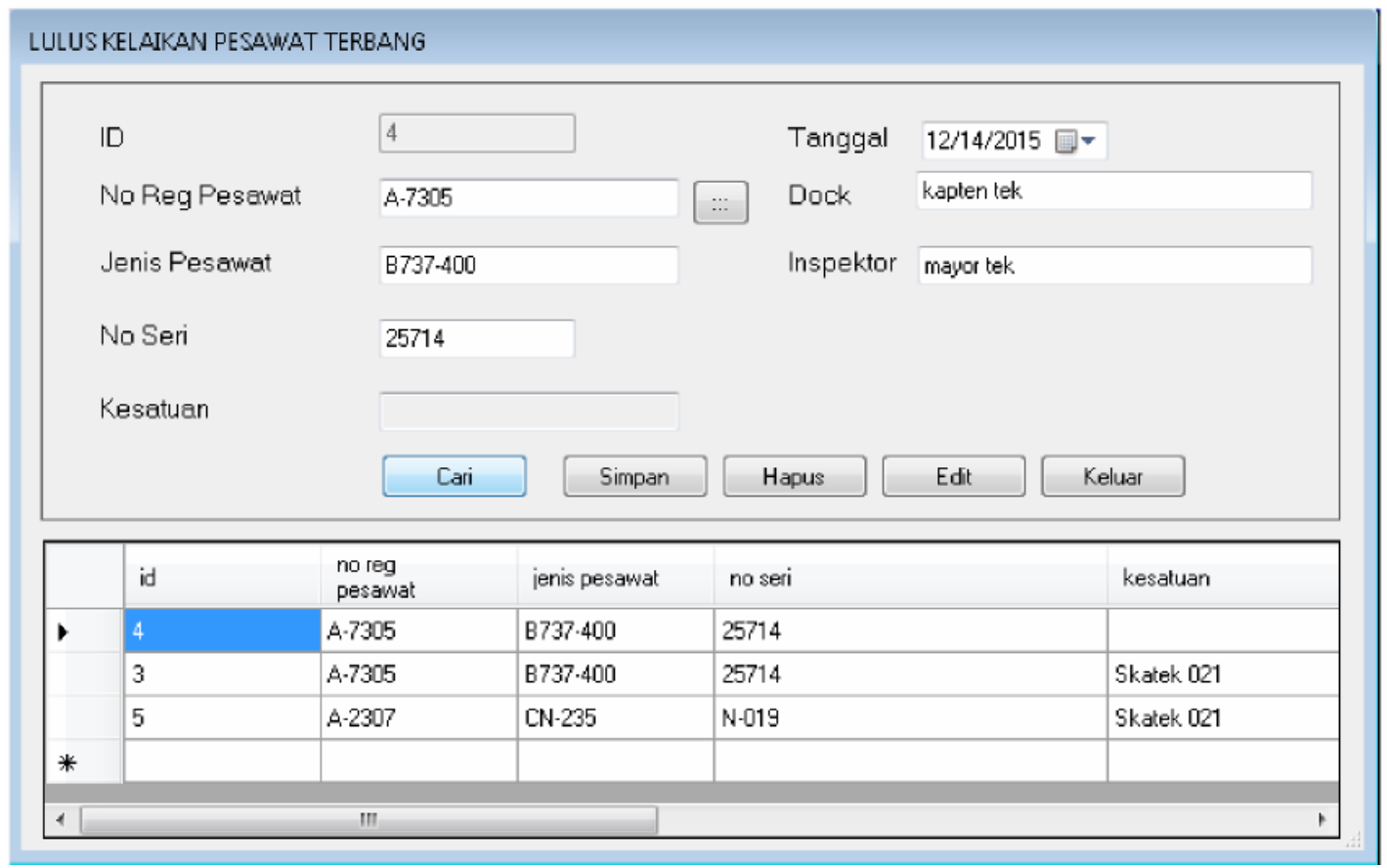

Stuktur tampilan Data Lulus Kelaikan 


\section{h) Stuktur tampilan Cetak Laporan Pemeliharaan}

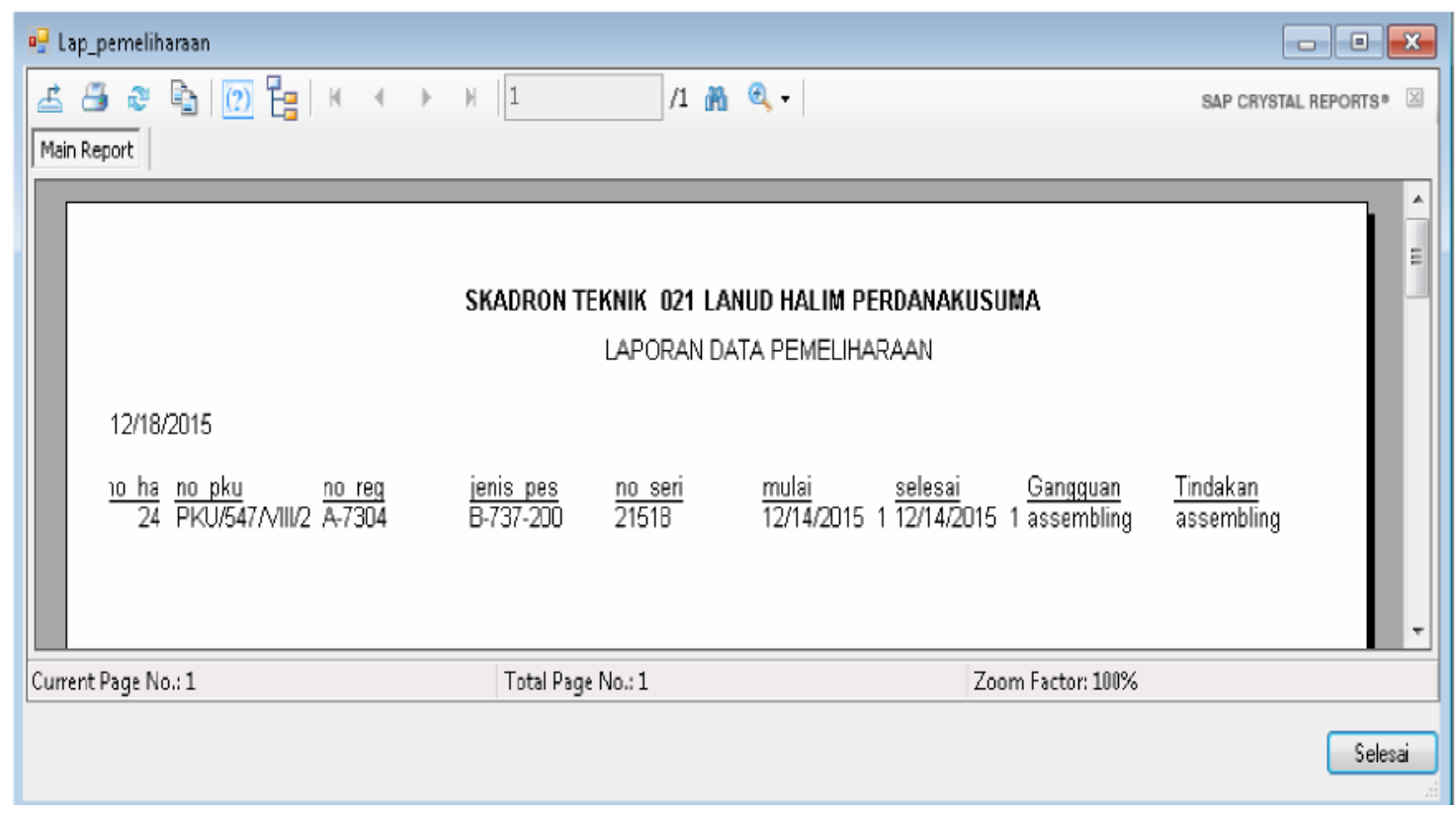

Stuktur tampilan Laporan Data Pemeliharaan

\section{i) Stuktur tampilan Cetak SKLP}

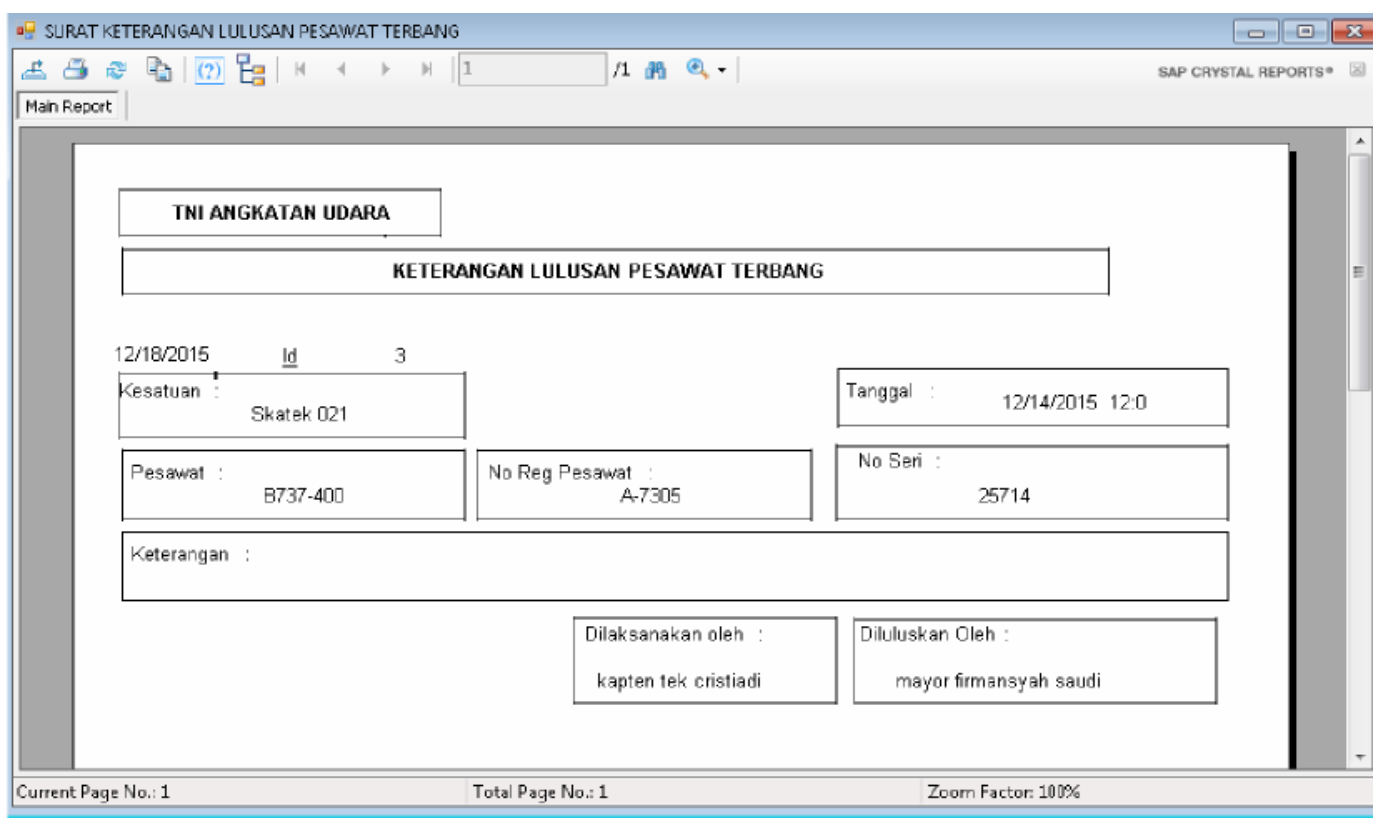

Stuktur tampilan Keterangan Lulusan Pesawat Terbang 


\section{PENUTUP}

\section{Kesimpulan}

Berdasarkan uraian-uraian dari pembahasan pada bab-bab yang ada untuk menjawab permasalahan yang ada dapat disimpulkan yaitu:

a. Memudahkan bagian pemeliharaan untuk mengetahui pesawat terbang yang sudah dilakukan pemeliharaan dari laporan pemeliharaan.

b. Dapat membuat Surat Keterangan Lulus Pesawat dan disimpan dalam database komputer.

c. Setiap serah terima pesawat data pesawat terbang bisa di masukan (input) ke komputer yang sudah terintegrasi database, jadi data dapat disimpan dan bisa dipergunakan jika sewaktu-waktu data dibutuhkan.

\section{Saran}

Dalam perancangan sistem informasi ini adalah agar dapat mempermudah pekerjaan di Skatek 021 Halim Perdanakusuma terutama dalam hal pembuatan.

a. Sebaiknya dalam sistem informasi administrasi pemeliharaan pesawat pada Skatek 021 Halim Perdanakusuma bisa menjadwalkan pemeliharaan secara periodik dalam sistem yang belum dilengkapi agar mempermudah mengetahui jadwal untuk setiap pesawat yang dipelihara .

b. Sebaiknya dilengkapi database personel yang melakukan pemeliharaan agar mempermudah dalam pencarian bila dibutuhkan tanpa harus ditulis kembali secara manual.

\section{DAFTAR PUSTAKA}

A, Dirwan. Analisa Penataan Ulang Organisasi Komando Utama TNI AU, 2013. ANGKASA CENDEKIA EDISI JULI 2008_Decrypted

Bambang S R-Perkembangan Kekuatan AURI2007-Surakarta

Bunga Ranuu- Sistem Informasi Manajemen2006

Djoko K, and Soeparno. Analisa penentuan interval waktu penggantian komponen kritis pd engine pesawat NC-212 Cassa.
2007

Jean, Marc P. Helicopter Flight Safety Enhancement a eurocopter continuing action, 2002.

Ainur, Dani and Bambang EP. Pembangunan SI Pengolahan Data nilai siswa berbasis web pd SMK Miftahul Huda N, 2014.

Aji, Teguh Y and Siswanto, Perancangan Sistem Informasi Pengadaan Barang dengan metode Object Oriented pada Bengkel Mas Auto Service. Semarang.

Dafit N H. Perancangan Sistem Informasi Tata Tertib Siswa Pada Smp Negeri 1 Jepara Dengan Menggunakan Sms Gateway, 2013.

Eka, Octavia P. Tek Penjadwalan proses produksi batik motif kembang api dg metode PER $T \& C P M$. Surakarta, 2010.

Hustinatul, Uun L. E-Goverment pd pekon ambarawa. Lampung

Julibate, Ari dkk. Analisa \& Perancangan Aplikasi Pengajaran B. Ingggris Berbasis Web. Palembang.

Putriani, Neti. Analisa dan Perancangan ECommerce pada Wisa Elektronik kemiling Bandar Lampung. Lampung

Rochmawati D and Valeria M W. Pengembangan Sistem Informasi Akuntansi Penjualan Dan Penerimaan Kas Berbasis Komputer, 2014.

Setiawan, Alexander dkk. Implementasi Sistem Penjadwalan Trucking dan Heavy Equipment Rental dengan AHP. Surabaya, 2009.

Sulastri, Tuti and Desi N. Perancangan Aplikasi administrasi Pengelolaan data paket pos dengan menggunakan Ms Access 2007 pada bagian PKC PT Pos Indonesia. Bandung, 2014.

Zainal, F A. Pembuatan program aplikasi database barang repair dengan PHP \& Mysql di PT Rekatama Putra Gegana. Bandung, 2012 
A, M Harits A. Strategi Pencegahan Kecelakaan Pesawat Terbang Militer Dalam Perspektif Ketahanan Nasional. Jakarta, 2011.

Andrian, Nanda. Perancangan Penjadwalan Dinas Kerja Lapangan $P d$ Kantor BBP2TP Medan Menggunakan Metode Bayes . Medan, 2013.

Supriyanto. Perbandingan Metode Terstuktur \& Objek Oriented Pada Analisis Desain Sistem. Bogor
Hanif Al Fatta. Analisis \& Perancangan Sistem Informasi. AndiYogyakarta. Yogyakarta. 2007.

Hengky W. Pramana. Kunci Sukses Pemograman Stock Inventory Berbasis Access 2000. PT Elex Media Komptaautindo Jakarta, 2003.

Aminah, Siti. Perancangan Sistem Informasi Persediaan barang pada PT Glostar Indonesia. Sukabumi, 2011. 